\title{
Neonatal Organ and Tissue Donation for Research: Options Following Death by Natural Causes
}

\author{
Martha Anderson • Stuart Youngner • Regina Dunne Smith • Raja R. Nandyal (1) • \\ Jeffrey P. Orlowski • B. Jessie Hill • Sarah Gutin Barsman
}

Received: 27 December 2019/Accepted: 2 March 2020/Published online: 13 March 2020

(C) Springer Nature B.V. 2020

\begin{abstract}
The donation of organs and tissues from neonates (birth to 28 days) for transplantation has been a relatively infrequent occurrence. Less common has been the use of neonatal organs and tissues for research. Specific ethical and legal questions beg for rational and transparent guidelines with which to evaluate referrals of potential donors. Donation of organs and tissues from a neonate can play a key role in the care and support provided to families by health care professionals around the time of a neonate's
\end{abstract}

M. Anderson

MTF Biologics, Edison, NJ, USA

e-mail: martha_anderson@mtf.org

S. Youngner $(\triangle)$

Department of Bioethics, School of Medicine, Case

Western Reserve University, 10900 Euclid Avenue,

Cleveland, OH 44106-4976, USA

e-mail: Sxy2@case.edu

R. D. Smith

International Institute for Advancement of Medicine,

Romansville, PA, USA

e-mail: gina_smith@iiam.org

R. R. Nandyal

Department of Neonatology, Oklahoma University Health

Sciences Center, Oklahoma City, OK, USA

e-mail: raja-nandyal@ouhsc.edu

J. P. Orlowski

LifeShare Transplant Donor Services of Oklahoma,

Oklahoma City, OK, USA

e-mail: jorlowski@lifeshareok.org death. We report on the recovery of neonatal organs and tissues for research. A working group made up of bioethicists, neonatologists, lawyers, obstetric practioners as well as organ procurement and tissue banking professionals evaluated legal, ethical and medical issues. Neonatal donor family members were also consulted. Our primary goals were (a) to ensure that referrals were made in compliance with all applicable federal and state laws, regulations and institutional protocols, and (b) to follow

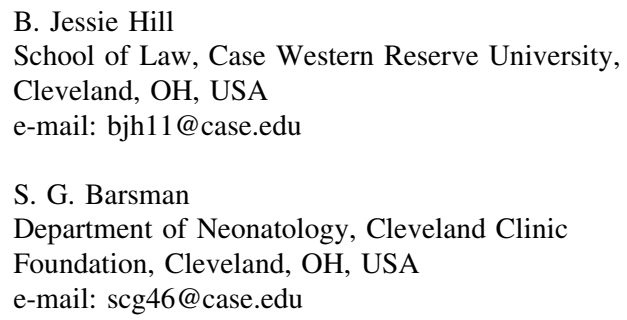


acceptable ethical standards. Algorithms and policies designed to assist in the evaluation of potential neonatal donors were developed. Neonatal donation is proving increasingly valuable for research into areas including diabetes, pulmonary, gastrointestinal, genitourinary and neurological development, rheumatoid arthritis, autism, childhood psychiatric and neurologic disorders, treatment of MRSA infection and pediatric emergency resuscitation. The development of policies and procedures will assist medical professionals who wish to offer the option of donation to family members anticipating the death of a neonate.

Keywords Organ donation - Research · Neonates · Anencephaly $\cdot$ Fetal demise

\section{Introduction}

The developing practice of using neonatal organs and tissues for research raises specific ethical and legal questions that beg for rational and transparent guidelines with which to evaluate referrals. This is especially true because of the rapidly increasing use of neonatal organs for research. To this end, a working group of scholars representing disciplines including bioethics, neonatology, obstetrics, and law, as well as professionals from Organ Procurement Organizations (OPO) and tissue banks including IIAM was formed. Neonatal donor families were also consulted. Its task was to consider the myriad of issues and to develop algorithms and policies for screening potential neonatal donors. Our primary goals were: (a) to ensure that referrals were evaluated in compliance with all applicable federal and state laws, regulations, and institutional protocols; and (b) to follow acceptable ethical standards.

\section{Background}

The donation of organs and tissues from neonates (birth to 28 days) for transplantation has been a relatively infrequent occurrence for a number of reasons, including a relative scarcity of recipients who are size matched to these small donors (Stiers et al. 2015; Boucek et al. 2018). Director of Research from the United Network for Organ Sharing Robert
Carrico shares that since 2010, annual totals of neonatal organ donors in the United States, both from donation after brain death (DBD) and donation after circulatory death (DCD), have ranged from 3 to 21 donors annually. This represents between 0.03 and $0.21 \%$ of organ donors recovered in any given year. The donation of neonatal organs and tissues for research is even less common than for transplantation, primarily because family members who receive a prenatal diagnosis of a lethal anomaly (LA) or experience the death of a neonate are not routinely offered information about research donation. Moreover, until recently researchers rarely sought neonatal organs and tissues.

In the mid-2010s, some families who received a pre-natal diagnosis of a LA such as anencephaly decided to carry their pregnancy to term regardless of the poor prognosis for long-term survival, often wishing to donate after the anticipated natural death of their neonate (Gray 2016a, b, c, d, e, f, g; Young 2017). Social media, blogs, and websites, including www.purposefulgift.org and www.anencephaly.info, have increasingly connected parents who receive a diagnosis of a LA. Some expectant parents began contacting the International Institute for the Advancement of Medicine (IIAM) with requests for assistance.

IIAM is among the largest 501c3 non-profit organizations in the U.S. that coordinates the placement of non-transplantable organs and tissues with Organ Procurement Organizations (OPOs) and researchers. IIAM is a division of MTF Biologics, one of the largest non-profit providers of donated human tissues (e.g., musculoskeletal, dermal and placental). Founded in 1986, IIAM annually receives over 15,000 referrals of non-transplantable organs and tissues authorized for research from donors from U.S. OPOs. In the past 20 years, they have placed more than 14,000 research organs. Matching donors and research projects is a challenging process, as researchers have very specific donor criteria and logistics requirements. Research organs provided by IIAM are used by academic researchers as well as by pharmaceutical and medical device companies in the U.S. and abroad.

At the same time, academic researchers began requesting neonatal organs through IIAM. Prior to this time, researchers had limited access to such organs and relied either on organs from adult donors or fetal tissue. No national guidelines or standards existed for 
the coordination of neonatal donation for research so referrals of potential neonatal donors were sporadic and managed on an ad hoc basis. They typically depended on the interest/capabilities of the individual OPO that would manage and coordinate the donation. As requests by expectant parents escalated, it became apparent that guidelines were necessary. The early interactions with expectant parents, OPO staff and researchers prompted the work that has resulted in this paper.

A more detailed taxonomy of acceptable and unacceptable donations appears later in this paper. After a brief discussion of ethical and legal issues as well as clinical ramifications of neonatal donation, we will explain how they helped shape our policy recommendations. Lastly, we will present data about the outcomes of more than 224 neonatal referrals. Although neonatal organs and tissues can be used for both transplantation and research, we will mainly focus on donation for research.

\section{Ethical and Legal Perspectives}

Neonatal organ and tissue donation represent a desire to make an altruistic gift and can play a key role in the care and support provided to families by hospital staff around the time of a neonate's death. Indeed, many families who have donated the organs and tissues of their deceased neonate reported that the decision brought them solace and comfort (Gray 2016a, b, c, d, e, f, g; Rhodes 2014; Purposeful Gift). Moreover, neonatal donation is proving increasingly important for research into a variety of areas, including determining the causes of neural tube defects (NTD); treating vision impairment; diabetes; organ system development; rheumatoid arthritis; pancreatic cancer; treatment of MRSA infection; pediatric emergency resuscitation (Gray 2016a, b, c, d, e, f, g; Aguayo-Mazzucato et al. 2017; Gregg et al. 2012; Ardini-Poleske et al. 2017; Cogger et al. 2017).

The primary goal of families with whom some of the authors (GDS, JO, MA, SBG) have interacted was to carry a fetus diagnosed with LA to term (or as close to term as possible) in order to achieve a live birth, knowing that aggressive treatment after birth would be futile. The possibility of organ and tissue donation was a secondary goal and provided an opportunity to find something positive in the midst of a tragic situation.
Legal and ethical questions that must be addressed require adherence to a variety of laws, regulations, and ethical principles. Various state and federal laws regulate the donation of organs and tissues regardless of the age of a potential donor. Federal law does not contain any restrictions that are uniquely relevant to neonatal organ and tissue donation. The federal National Organ Transplant Act (NOTA) and related regulations prohibit the sale of organs or tissues and creates a framework to facilitate and standardize the donation and recovery process (42 U.S.C. $\S 273$ et seq). At the state level, there are laws that may affect tissue and organ donation for research. For example, every state has an anatomical gift act that adopts some version of the Uniform Anatomical Gift Act (UAGA) (UAGA 2019). All states have adopted the Uniform Determination of Death Act (DDA), which describes the events that trigger the possibility of organ and tissue donation (DDA 1980). Organ and tissue donation must conform to the so-called Dead Donor Rule, which states that no patient's death may be caused by organ recovery (Robertson 1999).

Under the policies stipulated by the Organ Procurement and Transplant Network, it is mandatory to separate the medical care of a patient and the determination of death from the recovery of organs or tissues in all cases of donation (Organ Procurement and Transplant Network Policies (pp. 28-29) Available at: https://optn.transplant.hrsa.gov/media/1200/ optn_policies.pdf). If life-sustaining treatment is withdrawn, donation may occur if the patient dies and organ and tissue recovery can occur within a time period specified by the intended researcher.

Obtaining authorization for donation from parents of neonatal patients can be complex, and has received significant attention in previous studies (Martin et al. 2015). Typically, OPO staff conduct the authorization process, but they are not involved in the routine care of the neonate, or in determining or pronouncing the death of the neonate. Family members are given the latitude to determine which organs or tissues they wish to donate, and whether they wish to donate solely for transplantation or transplantation and research.

Some families may wish to donate organs in the context of actively terminating a pregnancy with an ultimately lethal outcome. The American College of Obstetricians and Gynecologists (ACOG) has established guidelines regarding medically acceptable indications for pre-term delivery for maternal or newborn 
benefit, but such a choice raises the legally and ethically fraught issue of abortion (Nicholson 2015; Committee Opinion No. 560 2013). Many state laws have unique implications for the legality of neonatal organ donation in certain circumstances. In particular, laws forbidding donation of, or research upon, tissue resulting from an abortion may be relevant in cases in which a pre-term delivery technically meets the statelaw definition of abortion. Recently, several states and the federal government have passed or considered such laws (Ark. Code $\S 20-17-802$, Ind. Code $\S \S$ 16-34-3-4(a); 16-41-16-4(d); 16-41-16-5; 16-41-167.6.; 15A N.C. Admin. Code 13B.1301.; 41 Tex. Reg. 9709-41). Although abortion is a legal medical procedure in the United States, for purposes of this project we rejected the possibility of accepting donations that resulted from abortions. Our guidelines do, however, allow acceptance of donations from some neonates who are delivered pre-term-but only if the delivery would not qualify as an abortion under applicable law.

Finally, we considered federal and state laws governing the withholding or withdrawing of lifesustaining care from disabled neonates. These laws, most specifically the Baby Doe Regulations (BDR) and the Born Alive Infant Protection Act (BAIPA), apply primarily to clinicians and hospitals that are directly involved in the pre-term delivery and subsequent care of a neonate, and do not constrain organ donation.

BDR and BAIPPA are federal laws that apply to pre-term delivery and resuscitation. BDR are federal statutory provisions that impose certain requirements on states as a condition of accepting federal Child Abuse Prevention and Treatment Act (CAPTA) funds (Pub.L. 98-457, 98 Stat. 1749 (codified as amended at 42 U.S.C. $\S \S 5101-5106 i$ (2006)). States are required to enact procedures for reporting and responding to "medical neglect," which is defined to include withholding treatment (including appropriate nutrition, hydration, and medication) from neonates with disabilities and life-threatening conditions (42 U.S.C. $\S 5106 \mathrm{a}(\mathrm{b})(2)(\mathrm{C}))$. This requirement imposes a fairly sweeping mandate to provide care for neonates born with potentially lethal conditions. There are, however, three exceptions to the requirement of providing medically indicated treatment. Treatment is not required if, "in the treating physician's or physicians' reasonable medical judgment:
- The neonate is chronically and irreversibly comatose";

- Providing treatment would only prolong the death of the neonate, would not be effective in correcting or ameliorating the conditions, or would "otherwise be futile in terms of the survival of the neonate" and,

- The treatment "would be virtually futile in terms of the survival of the neonate" and "the treatment itself under such circumstances would be inhumane" (42 U.S.C. $\$ 5106$ g(a)(5)).

The American Academy of Pediatrics and the Ethics Committee of the American College of Critical Care Medicine have both affirmed that it is ethically and legally justifiable to withhold or withdraw aggressive life-sustaining treatment in neonates when the burdens of such treatment far outweigh its benefits (Ethics Committee 2001; Committee on Bioethics 2013; Sarnaik 2015; AAP policy Statement 2010; Kon et al. 2016; Gries et al. 2013).

BAIPA is a second federal law that has an intent similar to that of BDR. BAIPA states that any infant who is "born alive," at any stage of development, must be treated as a person for purposes of the protections of federal law (1 U.S.C. $\S 8$ ). This law has long been viewed as symbolic legislation with an antiabortion message, since it is unclear that it has any actual impact on the application of any federal law. It might, however, mean that the Emergency Medical Treatment and Active Labor Act's (EMTALA) requirement of stabilizing patients who arrive at the hospital in an emergency condition would apply to very premature infants as well (42 U.S.C.A. $§ 1395 d d$ ) EMTALA, combined with the BAIPA, may therefore be understood to require some treatment of extremely premature infants who are born with a heartbeat or other signs of life. Futile or non-medically-indicated treatment would not likely be required for a very premature infant, since such treatment would not, within reasonable medical probability, prevent the neonate's condition from deteriorating.

Thus, as long as it is appropriate to characterize any care withheld from very premature neonates as being futile (in reasonable medical judgment), there is little danger of running afoul of BDR or BAIPA, as applied to EMTALA. 
Clinical Perspective

In 2015, there were 15,652 total U.S. neonatal deaths (3.93 per 1000 live births) (Murphy et al. 2017). Congenital malformations, deformations, and chromosomal abnormalities were noted to be primary causes of neonatal death. One such congenital malformation is anencephaly, one of the most common central nervous system disorders. Anencephaly is a neural tube defect that occurs when the cephalic (head) end of the neural tube fails to close, usually between the 23rd and 26th days of pregnancy; this results in the absence of the major portion of the brain, skull, and scalp. Some rudimentary forebrain, a part of the brain consisting mainly of the cerebrum, may exist. A functioning brainstem is usually present. Prenatal diagnosis of anencephalic neonates typically occurs at 12-14 weeks. The majority of anencephalic pregnancies are terminated early in the pregnancy (Brierley 2010; Stiers et al. 2015). The CDC estimates that anencephaly annually affects approximately 3 pregnancies in every 10,000, or 1206 pregnancies (CDC 2015). Most anencephalic neonates die within days or weeks without life-supporting interventions (Shewmon 1989).

The care of a mother carrying a baby with a LA can be complex, requiring close coordination between the obstetrician, neonatologist, and other healthcare professionals. In some instances, mothers experience a typical pregnancy except for the fact that they have received a diagnosis of a $\mathrm{LA}$; those who receive minimal or no prenatal care are unaware of a LA until the baby is born. In many cases, the syndrome or condition afflicting the fetus may cause concern for maternal, fetal, and/or both maternal and fetal health and may lead to a decision to induce pre-term (iatrogenic) labor. Alternatively, pre-term delivery may occur spontaneously without intervention. The leading causes for pre-term delivery are:

1. Spontaneous labor with intact membranes

2. Pre-term premature rupture of membranes (PPROM)

3. Delivery for maternal or fetal indications (Thakor et al. 2008).

Tucker reports that $15-25 \%$ of pre-term infants are iatrogenically delivered early because of maternal or fetal pregnancy complications (Tucker and McGuire 2004). Complications may include hypertension, preeclampsia or eclampsia, polyhydramnios, oligohydramnios, gestational diabetes, intrauterine growth restrictions, infection, and twin-to-twin transfusion syndrome.

Despite the recent widespread use of hypothermia therapy, Hypoxic Ischemic Encephalopathy (HIE) is a major cause of neurologic disabilities in term neonates. The incidence of HIE ranges from 1 to 8 per 1000 live births in developed countries and is as high as 26 per 1000 live births in underdeveloped countries (Douglas-Escobar and Weiss 2015). HIE neonates frequently receive ventilation, hypothermia, or other therapy, until brain death is confirmed or until a decision is made to withdraw treatment and to allow for a natural death, also known as "AND".

Medical literature is scant regarding discussion about neonates with HIE who became organ donors for transplantation or research. There are anecdotal reports of neonatal organ donation from HIE donors, including one author's center. Jadcherla, et al., reported a case of neonatal organ donation in a fullterm neonate with severe HIE complicated by multiorgan dysfunction who underwent therapeutic hypothermia (Bokisa et al. 2015). In non-ventilated cases, palliative care is provided to the neonate (hydration, comfort, etc.) allowing for a natural death (AND). It is at that point that criteria for DCD may be applied.

Medical challenges include working with hospital staff who may have inadequate information or awareness about the potential of neonates to become donors. Because transplant surgeons normally perform organ recovery only for transplant, OPO staff need to be trained in organ recovery for research. Specific details of the delivery of neonates can have a significant effect on the donation process-i.e., whether delivery occurred at term or prior to term; whether the neonate was delivered by natural delivery or whether labor was induced; the indications for medical intervention if labor was induced.

The criteria used for the acceptance of organ donors for research may vary, based on the type of research and individual research protocols. A neonate with LA may be considered as a potential donor for liver, lung, heart, kidney, pancreas, intestine, thymus, or tissue (skin, eyes, bone marrow, musculoskeletal and reproductive tissues). Multiple recipients or research studies can often benefit from a single donation. The researcher (or the protocol) needs to establish 
requirements such as minimum gestational age of the neonate. Exact time of death and a clear plan for organ recovery surgery have to be determined and documented. Donation must occur in a timely manner because of concern regarding the effect of warm ischemic time (WIT) on organ viability; this concern should be balanced with the family's need for time with their neonate after the neonate has passed away.

\section{OPO Perspective}

Neonatal donors, especially anencephalic donors, provide a unique set of challenges to an OPO. Whether the donation will ultimately result in transplanted organs or tissues, research organs or tissues, or some combination of these outcomes is often unclear until the surgical recovery occurs. The lack of formation of cerebral cortex and exposed brain structure make it impossible to determine brain death in anencephalic neonates. In other circumstances, such as HIE, it may be possible because the cerebral cortex is formed, and the skull structure is intact. In ventilated neonatal donors, including neonates with HIE, the process will often unfold in the same way as in older donors. Thus, coordinating neonatal anencephalic donation requires flexibility and establishment of contingency plans to maximize successful donation.

The challenges faced by OPOs in coordinating anencephalic donors fall largely into one of three categories: donor identification and referral; family and staff counseling; donation logistics. A brief discussion of each follows.

\section{Donor Identification and Referral}

In the United States, OPOs are to receive referrals on all in-hospital and imminent deaths. Most OPOs have established "clinical triggers" for referral, which include variables such as Glasgow Coma Scale 5 or below, discussion of withdrawal of care, initiation of brain death testing, or cardiac arrest. In the context of ventilated neonatal donors, these clinical triggers may apply; in anencephalic donors, who are typically nonventilated, they will not. The challenge, therefore, is to establish referral processes for practitioners working with the families of anencephalic neonates, to educate both OPO staff and donor hospital professionals about neonatal donation, and to implement protocols for both OPO and hospital staff to manage these cases. Sample protocols are available upon request to IIAM (www.iiam.org).

\section{Family and Staff Counseling}

The standard approach for OPOs in terms of counseling donor family and hospital staff regarding donation begins with the initial referral and after an evaluation of the clinical suitability for donation. Because the timing of a referral is quite different in the anencephalic donor, two variables come into play. First, the donor family may be several months short of the actual delivery and will have much more time to consider their options for donation. This is unusual and requires multiple follow-ups with a family over an extended period as their decision-making evolves. Second, the context of the discussions with perinatal and neonatal practitioners regarding the pregnancy and other related decisions is quite different from traditional organ donor situations, in which the discussion centers around brain death, withdrawal of care in a patient who is not brain dead and helping the family come to grips with the finality of the patient's brain injury.

With anencephalic neonates, the family is addressing a far different set of issues, such as whether to carry to term and development of an appropriate birth plan. The process typically proceeds as with any organ/tissue donor referral in scenarios with HIE or LA.

\section{Donation Logistics}

In standard DBD or DCD scenarios, regardless of the age of the potential donor, OPOs obtain authorization for donation, evaluate organ function, attempt to maximize organ function, match organs to recipients, and then coordinate the surgical recovery, which may include allowing teams from distant centers to fly to the hospital for the surgical recovery. Surgical recovery is scheduled after organ evaluation and preliminary acceptance by a transplant center or, in the case of research donation, by a researcher. Donor blood type, height, weight, and many other data factor into this process.

A ventilated neonatal donor will follow much the same path. Anencephalic donors are not typically intubated. As a result, the OPO will have limited clinical information about the donor. It is vital to 
underscore that no donation can take place until death has occurred, through the pronouncement of death either by neurological criteria (i.e., brain death) or by circulatory death. OPOs can implement a few key strategies to maximize the benefit of the donation for the neonatal donor family, transplant recipients, and researchers. They include:

1. Proactively identify centers where these potentially complex cases may be referred and transplant centers willing to consider neonatal organs for transplant.

2. Have research outlets for all possible organs and tissues since transplantation rarely occurs with these potential donors.

3. Closely collaborate with the specialists caring for the mother and neonate. It is not uncommon for these cases to unfold over months.

4. Have at least two OPO staff supporting and counseling the family. The prolonged process of neonatal donation and the importance of bonding with the family require a team approach in order to avoid compassion fatigue (Nicely and Delario 2011; Maloney and Wolfelt 2011; Larowe 2005).

\section{Experience with Neonatal Donors for Research}

In 2012, Bethany C., who was pregnant with an anencephalic baby, contacted IIAM. She wanted to donate her son's organs and tissues following his death. Despite contacting her obstetrician, local medical schools and hospitals, and the OPO that serves her hometown, she had been unsuccessful. She found IIAM's website and contacted IIAM just days before her scheduled C-section. Within $2 \mathrm{~h}$, IIAM found researchers who were willing to accept her baby's liver and pancreas, and another researcher who was interested in receiving his entire body after organ donation. Their son, Amalya Nathaniel, lived for $80 \mathrm{~min}$, surrounded by his parents, maternal and paternal grandparents, and other extended family members. The OPO performed the organ recovery after his death. As a result of his donation, researchers were able to evaluate pancreatic beta cells in their earliest stages of development, leading them to understand why some people develop Type 1 Diabetes; other researchers studied hepatocytes, which is critical to understanding cell generation. Images generated by his body led to FDA clearance for a medical device used for rapid pediatric resuscitation (ArdiniPoleske et al. 2017; Li et al. 2018; Gray 2016a, b, c, $\mathrm{d}, \mathrm{e}, \mathrm{f}, \mathrm{g})$.

Between 2012 and 2017, IIAM coordinated the recovery of organs and tissues from 86 donors, placing 281 organs and tissues. Most neonates who became donors were anencephalic (60\%), followed by neonates who died because of anoxia or HIE (23\%). Other causes of death included Trisomy 18, fatal cardiac and renal anomalies, trauma, and other genetic and neurological conditions.

Gestational age (GA) varied, with the majority being delivered at term (which includes early term, full term and late term; 37 0/7 weeks-41 6/7 weeks) (see Fig. 1) (Taylor et al. 2019). Pre-term deliveries (20 0/7 weeks-36 6/7 weeks) often occurred for medically indicated reasons (either maternal or fetal health or both); the majority of these deliveries were iatrogenic. Pre-term deliveries for non-medical reasons were not accepted as referrals. One was referred following miscarriage at 16 weeks and was able to donate skin.

All of the families who pursued donation did so with the intent of having a live birth, spending as much time as possible with the neonate, and donating, if possible, after the neonate's death. The time elapsed from birth to death ranged from minutes to days (See Fig. 2). In most cases, the neonate remained in the Labor and Delivery area; on one occasion, the neonate was taken home, given hospice care, and then her body was returned to the hospital following her death at 5 days.

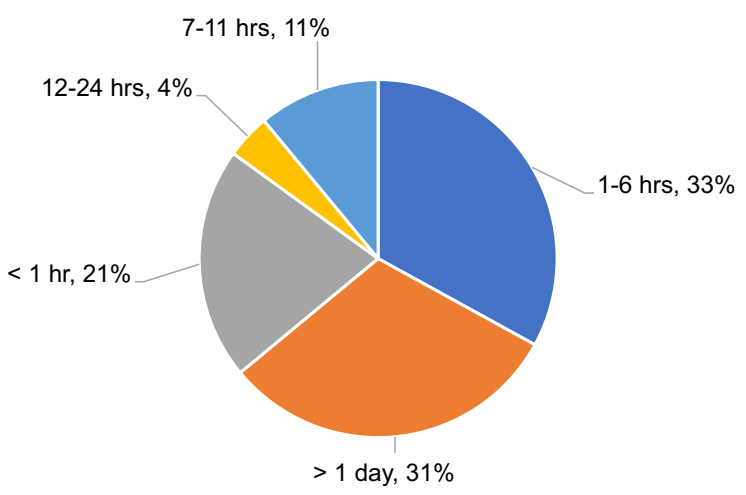

Fig. 1 Time Elapsed from Birth to Death 2012 to June 2019 


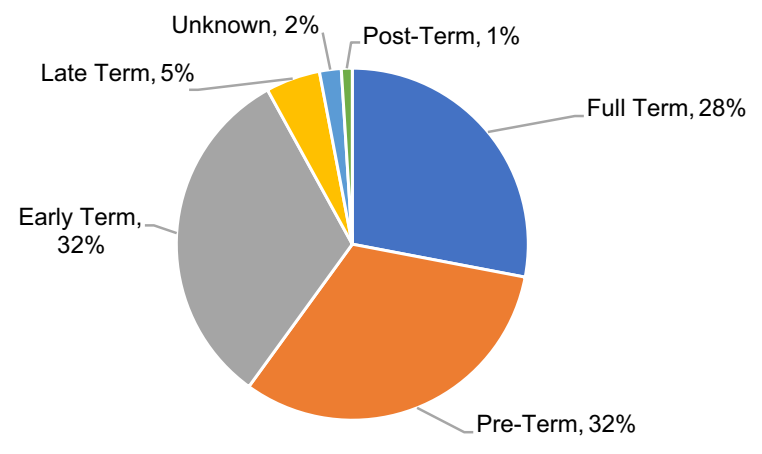

Fig. 2 Gestational Age 2012-June 2019

Considering the legal, medical, ethical and practical issues surrounding these donation opportunities, the working group developed a set of algorithms designed to guide staff from OPOs and IIAM in evaluating potential donors. Three separate algorithms were developed: one for neonates being delivered at term with a LA (See Fig. 3); one for neonates being born pre-term with a LA (See Fig. 4); one for neonates who die as a result of other conditions, such as HIE or trauma (See Fig. 5). Referrals are now evaluated according to these algorithms. Reasons for declining referrals of potential neonatal donors include:

- Iatrogenic labor planned to terminate a pregnancy, not for maternal and/or fetal health (1\%)

- GA less than 24 weeks (3\%)

- Extended Cold Ischemic Time (CIT) or Warm Ischemic Time (WIT) (11\%)

- Diagnosis/medical condition (12\%)

- Unable to identify available researchers (13\%)

- Family withdrew offer (19\%)
a. Family withdrew offer
b. Family did not call OPO back after initial inquiry
c. Family declined donation

- OPO withdrew offer (41\%)
a. OPO did not have an internal policy for neonatal donation
b. OPO did not have the skill set or appropriate procurement setting
c. OPO would not proceed unless an organ would also be recovered for transplant
d. Medical Director refused authorization

Researchers who accepted neonatal organs and tissues through this program study such diverse areas as regenerative medicine, diabetes, chronic kidney disease, cancer, congenital organ malformation, abnormal lung development, and fertility (See Fig. 6). Pulmonary research in particular, has been advanced using donated neonatal lungs. Over 75 neonatal donors have been provided to the Biorepository for the Investigation for Diseases of the Lung (BRINDL)/University of Rochester Medical Center (URMC) Human Tissue Core and distributed to more than 10 other academic laboratories. BRINDL and the URMC Human Tissue Core are responsible for all the human data that currently appears on LungMAP.net. Papers and presentations arising from the LungMAP project primarily focus on characterization of neonatal lung cells, and clinical and translational studies in rare lung diseases. This project has also explored why neonates and infants frequently progress to severe lung failure when exposed to Respiratory Syncytial Virus (RSV) versus adults whose systems respond to RSV in a less severe manner. This information is expected to provide new options for treatment and prevention (Taylor et al. 2019; Jiang et al. 2019; Wang et al. 2019; Lal et al. 2018; Whitsett 2018; Kyle et al. 2018; Bandyopadhyay et al. 2018; Luo et al. 2018; Zhu et al. 2018; Zhou et al. 2018; Ardini-Poleske et al. 2017; Warburton 2017; Du et al. 2017). Research findings from other projects using neonatal organs have been presented at scientific conferences and published in scientific journals (Gray 2016a, b, c, d, e, f, g; ArdiniPoleske et al. 2017; Gittinger 2015). Placements of research organs and tissues range from one organ per donor to over ten organs and tissues per donor.

\section{Conclusion}

Donation of organs and tissues for research from neonates who die following a live birth has recently become an option some families wish to consider. Pursuing this donation option requires careful attention to legal, ethical, medical, and procedural issues. It is vital to ensure that the integrity of the donation process be safeguarded, and that the desire to support neonatal donor families does not compromise ethical and legal standards. The comfort and solace that donation provides following the death of a neonate can be vital to families' healing processes and should be 


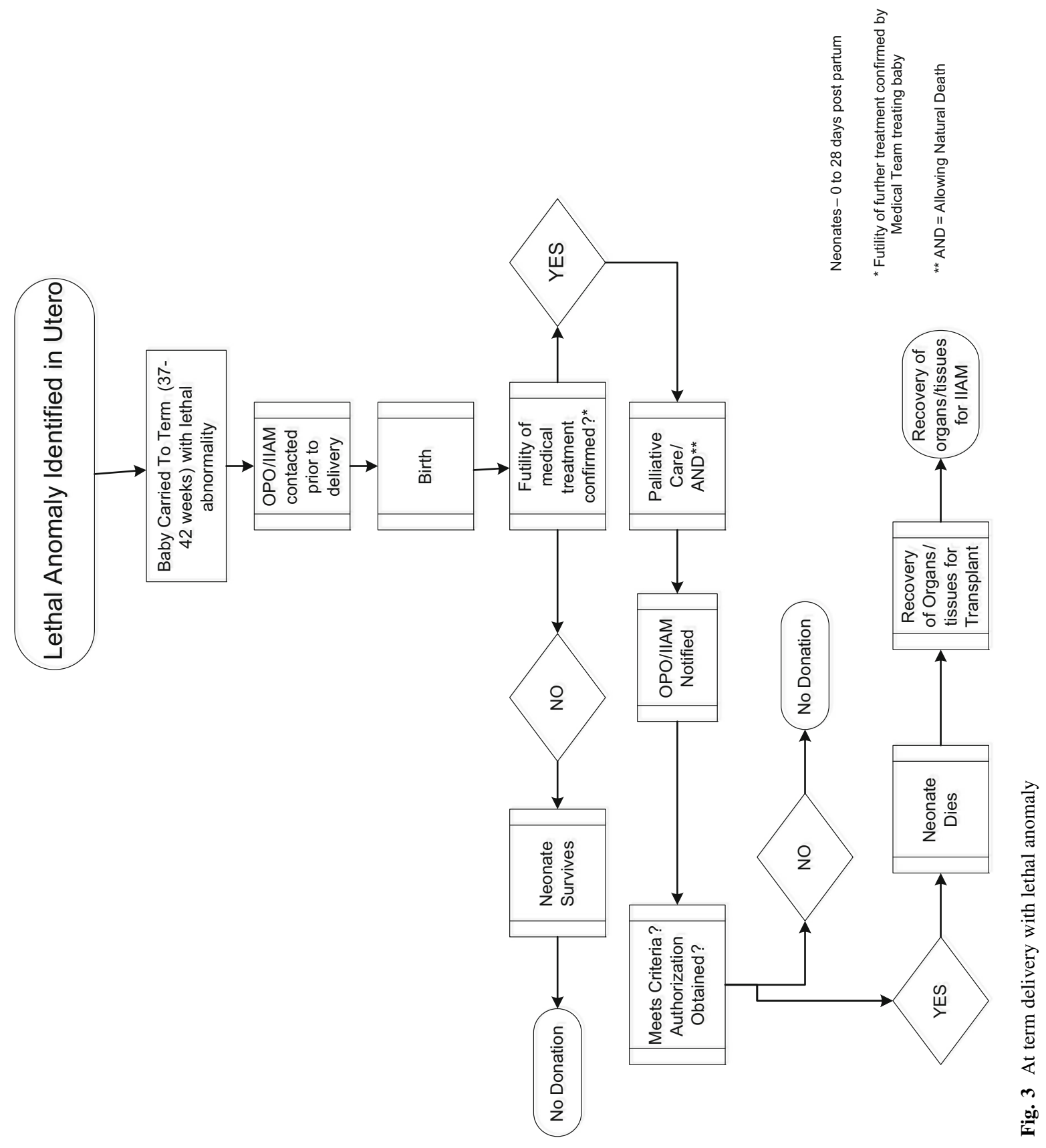




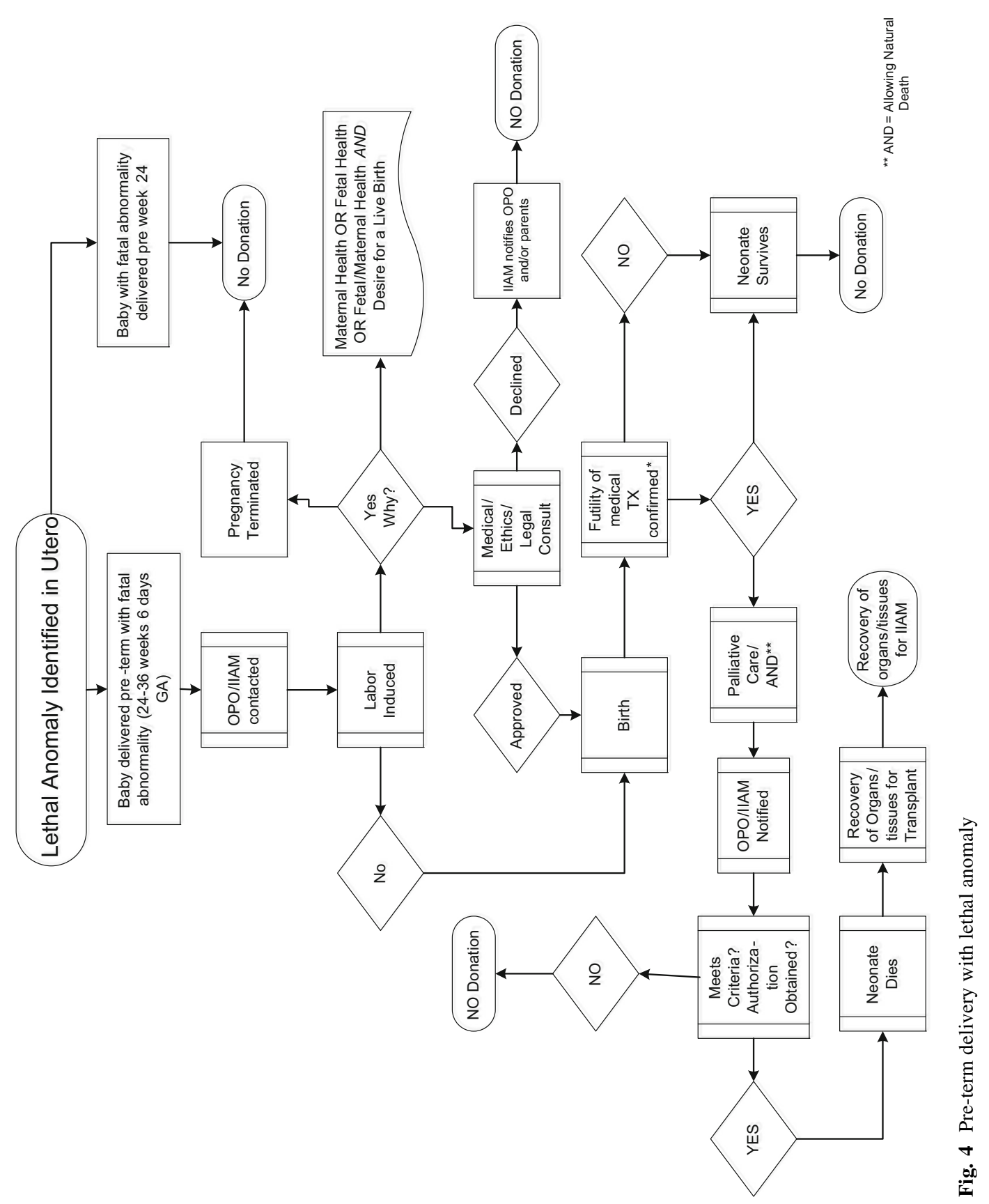




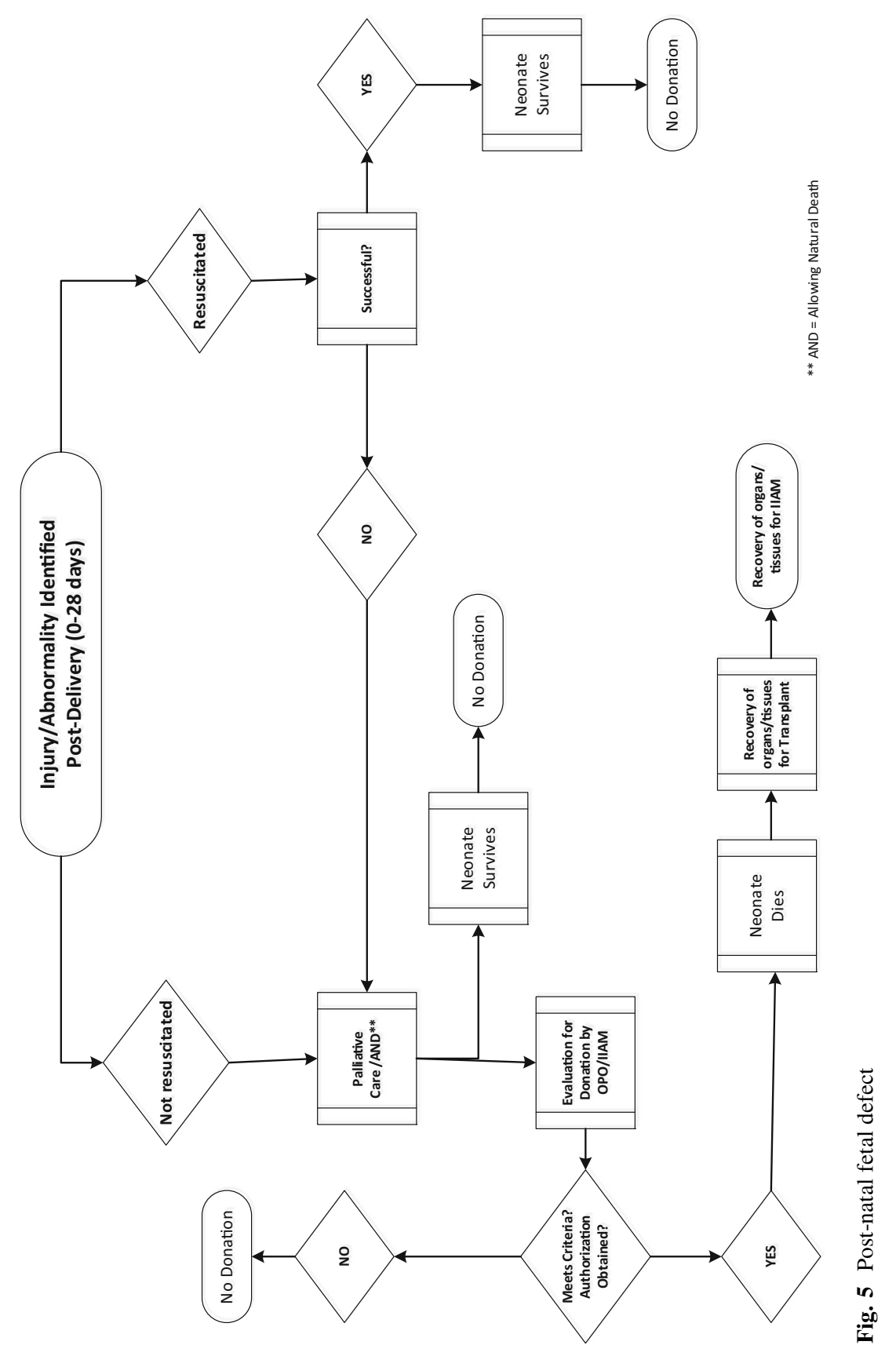




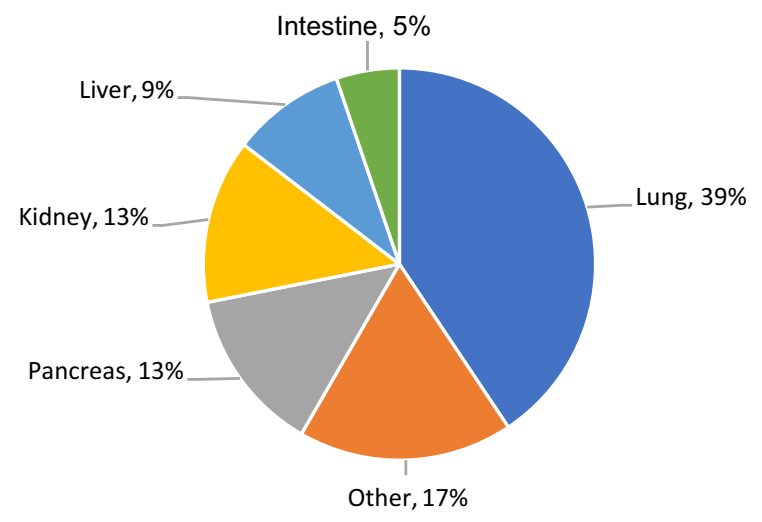

Fig. 6 Neonatal placements 2012-June 2019

supported whenever possible. Given the potential legal and ethical barriers to donation and the fact that not all OPOs are currently equipped to provide this service even if the request falls within acceptable standards, it is important that families have realistic expectations with respect to donation opportunities.

Coordinating neonatal referrals requires careful collaboration between hospital administration, health care professionals, OPO staff, staff of the agency interfacing with researchers and OPOs, and the researchers themselves.

The uses of neonatal organs and tissues have led to remarkable breakthroughs in science. Family donation of organs and tissues from a neonate represents a desire to make an altruistic gift and can play a key role in the care and support provided to families by hospital staff at the time of a neonate's pending death. Family members who suffer the tragic loss of a newborn through either congenital abnormalities such as anencephaly, or situations arising from a traumatic birth or HIE, have found "unexplainable peace, joy and healing" in their ability to donate, thereby allowing their child to make an "impact on the world" (Rhodes 2014).

Author's contribution MA: conceptualization, research, writing, RDS: conceptualization, research, writing, SGB: research, writing, BJH: conceptualization, research, writing, RRN: research, writing, JPOi: research, writing, SY: conceptualization, research, writing.

Funding MTF Biologics provided funding for the development of the project.The authors wish to thank Wee Siang Tay for his assistance with references.

\section{References}

AAP policy Statement-Pediatric Organ Donation and Transplantation

Aguayo-Mazzucato C, van Haaren M, Mruk M et al (2017) $\beta$ cell aging markers have heterogeneous distribution and are induced by insulin resistance. Cell Metab 25(4):898-910

Ardini-Poleske ME, Clark RF, Ansong C et al (2017) LungMAP Consortium. LungMAP: the molecular atlas of lung development program. Am J Physiol Lung Cell Mol Physiol 313(5):L733-L740. https://doi.org/10.1152/ ajplung.00139.2017

Bandyopadhyay G, Huyck HL, Misra RS et al (2018) Dissociation, cellular isolation, and initial molecular characterization of neonatal and pediatric human lung tissues. Am J Physiol Lung Cell Mol Physiol 315(4):L576-L583. https:// doi.org/10.1152/ajplung.00041.2018

Bokisa A, Bonachea E, Jadcherla S (2015) Death by neurologic criteria in a neonate: implications for organ donation. J Neonatal Perinat Med 8(3):263-267. https://doi.org/10. 3233/npm-15814074

Boucek M, Mashburn C, Dunn S, Frizell R, Edwards L, Pietra B, Campbell D (2018) Pediatric heart transplantation after declaration of cardiocirculatory death. New Engl J Med 2008(359):709-714

Brierley J (2010) Neonatal organ donation: has the time come? Arch Dis Child Fetal Neonatal Ed. https://doi.org/10.1136/ adc. 2010.192757

Centers for Disease Control and Prevention. Updated Estimates of Neural Tube Defects Prevented by Mandatory Folic Acid Fortification - United States, 1995-2011. https:// www.cdc.gov/mmwr/preview/mmwrhtml/mm6401a2. htm. Published January 16, 2015. Accessed 11 July 2018

Cogger KF et al (2017) Glycoprotein 2 is a specific cell surface marker of human pancreatic progenitors. Nat Commun. https://doi.org/10.1038/s41467-017-00561-0

Committee on Bioethics (2013) Ethical controversies in organ donation after circulatory death. Pediatrics 131(5):1021-1026. https://doi.org/10.1542/peds.20130672

Committee Opinion No. 560 (2013) Obstetrics and Gynecology. 121(4):908-910. https://doi.org/10.1097/01.aog. 0000428648.75548 .00

Douglas-Escobar M, Weiss MD (2015) Hypoxic-ischemic encephalopathy: a review for the clinician. Adv Ped 169(4):397-403. https://doi.org/10.1001/jamapediatrics. 2014.3269

Du Y, Kitzmiller JA, Sridharan A, Perl AK et al (2017) Lung gene expression analysis (LGEA): an integrative web portal for comprehensive gene expression data analysis in lung development. Thorax 72(5):481-484. https://doi.org/ 10.1136/thoraxjnl-2016-209598

Ethics Committee (2001) American college of critical care medicine, society of critical care medicine: recommendations for non-heartbeating organ donation. Crit Care Med 29(9):1826-1831

Gittinger E. (2015) Normal Delivery of the Infant: Overview, Indications, Contraindications. Bckgrd, Pathophys, Eti.. Available at: emedicine.medscape.com/article/83021overview 
Gray S (ed) (2016a) Amalya's story. In: A Life Everlasting. HarperCollins, New York, p 171

Gray S (ed) (2016b) Amalya's story. In: A Life Everlasting. HarperCollins, New York, pp 164-165

Gray S (ed) (2016c) Amalya's story. In: A life everlasting. HarperCollins, New York, p 170

Gray S (ed) (2016d). Eli's story. In: A life everlasting. HarperCollins, New York, p 91

Gray S (ed) (2016e) Sophie's choice: backward at $100 \mathrm{mph}$. In: A life everlasting. HarperCollins, New York, p 26

Gray S (ed) (2016f) The dance. In: A life everlasting. HarperCollins, New York, p 173

Gray S (ed) (2016g) Thomas's ride. In: A life everlasting. HarperCollins, New York, p 76

Gregg BE, Moore PC, Demozay D et al (2012) Formation of a human $\beta$-cell population within pancreatic islets is set early in life. J Clin Endocrinol Metab 97(9):3197-3206

Gries CJ, White DB, Truog RD et al (2013) an official american thoracic society/international society for heart and lung transplantation/society of critical care medicine/association of organ and procurement organizations/united network of organ sharing statement: ethical and policy considerations in organ donation after circulatory determination of death. Am J Respir Care Med 188(1):103-109. https://doi.org/10.1164/rccm.201304-0714st

Jiang Y, Luo Y, Tang Y, Moats R et al (2019) Alteration of cystic airway mesenchyme in congenital pulmonary airway malformation. Sci Rep 9(1):5296. https://doi.org/10. 1038/s41598-019-41777-y

Kon AA, Shepard EK, Sederstrom NO et al (2016) defining futile and potentially inappropriate interventions. Crit Care Med 44(9):1769-1774. https://doi.org/10.1097/ccm. 0000000000001965

Kyle JE, Clair G, Bandyopadhyay G, Misra RS et al (2018) Cell type-resolved human lung lipidome reveals cellular cooperation in lung function. Sci Rep. 8(1):13455. https://doi. org/10.1038/s41598-018-31640-X

Lal CV, Bhandari V, Ambalavanan N (2018) Genomics, microbiomics, proteomics, and metabolomics in bronchopulmonary dysplasia. Semin Perinatol 42(7):425-431. https://doi.org/10.1053/j.semperi.2018.09.004

LaRowe K (2005) Breath of relief. Acanthus Publishing, Boston

Li AP, Ho D, Ring N, Amaral K (2018) A comparison of adult and neonatal human hepatocytes in drug metabolizing enzyme activities. Drug Metab Pharmacokinet 33(1):S80

Luo Y, Li N, Chen H, Fernandez GE et al (2018) Spatial and temporal changes in extracellular elastin and laminin distribution during lung alveolar development. Sci Rep 8(1):8334. https://doi.org/10.1038/s41598-018-26673-1

Maloney R, Wolfelt AD (2011) Caring for donor families; before, during and after, 2nd edn. Companion Press, Fort Collins

Martin DE, Nakagawa TA, Siebelink MJ et al (2015) Pediatric deceased donation-a report of the transplantation society meeting in geneva. Transplantation 99(7):1403-1409. https://doi.org/10.1097/tp.0000000000000758

Murphy SL, Xu J, Kochanek KD, Curtin SC, Arias E. Deaths: final data for 2015. National Vital Statistics Reports. https://www.cdc.gov/nchs/data/nvsr/nvsr66/nvsr66_06. com. Published November 27, 2017. Accessed 10 July 2018
Nicely B, Delario G (2011) Virginia henderson's principles and practice of nursing applied to organ donation after brain death. Prog Transpl 21(1):72-77. https://doi.org/10.7182/ prtr.21.1.c7617103jug3466m

Nicholson JM (2015) The 39-week rule and term stillbirth: beneficence, autonomy, and the ethics of the current restrictions on early-term labor induction in the US. BMC Pregnancy Childbirth. https://doi.org/10.1186/1471-239315-s1-a9

Organ Procurement and Transplant Network. Policies (pp 28-29). https://optn.transplant.hrsa.gov/media/1200/optn_ policies.pdf. Accessed 22 December 2018. Last updated 24 Oct 2019. 10/24/2019

Purposeful Gift. http://purposefulgift.com/en/. Accessed 10 July 2018

Rhodes R The littlest donors: neonatal organ donation offers hope in tragedy. NBCNews.com. March 18, 2014. https:// www.nbcnews.com/health/kids-health/littlest-donorsneonatal-organ-donation-offers-hope-tragedy-n51436. Accessed 10 July 2018

Robertson J (1999) The dead donor rule. Hastings Center Rep 29(6):6-14. https://doi.org/10.2307/3527865x

Sarnaik AA (2015) Neonatal and pediatric organ donation: ethical perspectives and implications for policy. Front Pediatr 3:100. https://doi.org/10.3389/fped.2015.00100

Shewmon DA (1989) The use of anencephalic infants as organ sources. JAMA 261(12):1773. https://doi.org/10.1001/ jama.1989.03420120111036

Stiers J, Aguayo C, Siatta A, Presson AP, Perez R, Digeronimo $R$ (2015) Potential and actual neonatal organ and tissue donation after circulatory determination of DEath. JAMA Pediat 169(7):639. https://doi.org/10.1001/jamapediatrics. 2015.0317

Taylor DM, Aronow BJ, Tan K et al (2019) The pediatric cell atlas: defining the growth phase of human development at single-cell resolution. Dev Cell 49(1):10-29. https://doi. org/10.1016/j.devcel.2019.03.001

Thakor A, Hiemstra T, Jayne D (2008) Anaemia, weight loss, and round shadows in the lungs. Lancet 371(9606):88

Tucker J, McGuire W (2004) Epidemiology of preterm birth. BMJ 329(7467):675-678

Wang Q, Bhattacharya S, Mereness JA et al (2019) A novel in vitro model of primary human pediatric lung epithelial cells. Pediatr Res. https://doi.org/10.1038/s41390-0190340-9

Warburton D (2017) Overview of lung development in the newborn human. Neonatology 111(4):398-401. https://doi. org/10.1159/000458465

Whitsett JA (2018) Airway epithelial differentiation and mucociliary clearance. Ann Am Thorac Soc 15(Supplement_3):S143-S148. https://doi.org/10.1513/annalsats. 201802-128aw

Young R We spent months bracing and preparing for the death of our daughter. But guess what? We weren't ready. Medium. https://medium.com/@ royceyoung/we-spentmonths-bracing-and-preparing-for-the-death-of-ourdaughter-79f357dd254d. Updated April 27, 2017. Accessed 10 July 2018

Zhou Y, Horowitz JC, Naba A et al (2018) Extracellular matrix in lung development, homeostasis and disease. Matrix Biol 73:77-104. https://doi.org/10.1016/j.matbio.2018.03.005 
Zhu Y, Clair G, Chrisler WB et al (2018) Proteomic analysis of single mammalian cells enabled by microfluidic nanodroplet sample preparation and ultrasensitive NanoLCMS. Angew Chem Int Ed Engl 57(38):12370-12374. https://doi.org/10.1002/anie.201802843
Publisher's Note Springer Nature remains neutral with regard to jurisdictional claims in published maps and institutional affiliations. 